\title{
The nose, snoring and obstructive sleep apnoea
}

\author{
Bhik Kotecha \\ Royal National Throat, Nose \& Ear Hospital, London, United Kingdom
}

SUMMARY

\begin{abstract}
Snoring and obstructive sleep apnoea are both due to multilevel anatomical obstruction, and the nose and nasal pathology both contribute in many cases. This paper addresses some of the issues surrounding the problem and briefly discusses the role of medication and nasal dilators and in more detail the implication of nasal surgery in various aspects of sleep related breathing disorders $(S R B D)$. Nasal obstruction leads to mouth breathing, which destabilises the upper airway and aggravates $S R B D$.
\end{abstract}

Key words: snoring, obstructive sleep apnoea, nasal obstruction, nasal surgery

Historically, even in the Hippocratic era it was thought that the nose played a role in snoring and caused restless sleep. Five years ago, in this journal, Rhombaux et al. ${ }^{(1)}$ published a review article on nasal obstruction and its impact on sleeprelated breathing disorders. Subsequently there has been a prolific increase in the number of articles published on the subject. Though nasal and sleep physiology as well as mechanisms relating to upper airway obstruction remain significantly unchanged, data and information derived from more recent medical and surgical trials have made a useful addition. In particular, evaluating treatment outcomes more objectively and the use of quality of life (QoL) questionnaires have added a different dimension.

Sleep-related breathing disorder (SRBD) is essentially a spectrum consisting of various clinical entities ranging from simple or primary snoring at one end to severe obstructive sleep apnoea at the other ${ }^{(2)}$. The prevalence of snoring in middleaged men is in the range of $25-50 \%{ }^{(3,4)}$, whereas OSA affects 2 $4 \%$ of males and $1-2 \%$ of females ${ }^{(5)}$. The use of dynamic MRI imaging, acoustic analysis, sedation endoscopy and pharyngeal luminal pressure recordings have helped establish the fact that both snoring and OSA exhibit a multilevel phenomenon ${ }^{(6-9)}$ whereby obstruction occurs in the naso, oro and hypopharynx in differing proportions in different patients. The first port of entry for the air is indeed the nasal vestibule, thus the nose and various nasal pathology can have a significant impact on the collapsibility of different segments of the pharyngeal lumen $(10,11)$.

Various laws of physics and theories of dynamics are required to fully explain the relationship between nasal airflow, obstruction and SRBD. Included in this would be the Starling resistor model, Bernoulli and Venturi effects. The main theories proposed to link nasal obstruction and SRBD have 3 main components namely increase in nasal resistance, the unstable oral breathing and the impaired nasal reflexes
(10,12-17). As a reflex compensatory mechanism secondary to nasal obstruction, mouth breathing commences resulting in narrowing of pharyngeal lumen, a decrease in the retroglossal dimension as a result of further posterior retraction of the tongue and an increase in the oscillation and vibration of the soft palate and redundant pharyngeal tissue. The influence of posture is well recognised in that the nasal resistance increases in the recumbent position due to the hydrostatic component ${ }^{(1,11)}$. This could be explained by an increase in the jugular venous pressure. Nitric oxide is also thought to play a role in maintaining upper airway patency by acting as an aerotransmitter between the nose and the lung ${ }^{(18)}$.

Anatomically, the nose is far less collapsible than the pharynx as it has a rather rigid framework with the exception of the nasal valve region. Nasal obstruction experienced by patients could be due to structural abnormalities (e.g. deviated nasal septum, enlarged turbinates, and nasal valve collapse), mucosal disease (rhinitis, sinusitis, nasal polyposis) or more rarely due to neuromuscular problem. Imposed obstruction secondary to nasal packing can lead to reduced oxygen saturation levels and SRBD $^{(19)}$.

Numerous studies have demonstrated that chronic nasal congestion is associated with snoring ${ }^{(20,21)}$ and daytime sleepiness ${ }^{(22,23)}$. An epidemiological study ${ }^{(24)}$ has revealed that allergic rhinitis affects $9-42 \%$ of the population. The mechanism by which allergic rhinitis causes poor sleep quality and daytime fatigue is not entirely clear but it is thought that multiple factors are involved and these include the various inflammatory mediators, which may have a direct effect on sleep regulation ${ }^{(25,26)}$, nasal obstruction, postural changes and adverse effects of some antihistamines used to treat the condition. A study by Kohler et al. (27) has addressed the issue of perception of nocturnal nasal obstruction in patients with chronic rhinitis, demonstrating the presence of nasal cycle during sleep. 
To overcome nasal obstruction, treatment options available are medication, nasal dilators and surgical intervention. Clinical trials have been conducted in all above-mentioned categories but they lack uniformity in that, not all studies have looked at objective outcome measures. Many of the studies are nonrandomised, lacking controls, have small number of patients included and the follow-up period is relatively short.

\section{Medical treatment}

In patients with chronic rhinitis, the main cause of the high nasal resistance is due to the excessive swelling and engorgement of nasal mucosa. In terms of conservative treatment, this could be overcome by the use of topical application of steroids or sympathomimetic decongestants. The way in which medication works is due to reduction in inflammatory mediators or indeed as a result of direct mechanical reduction of nasal congestion, thus leading to a decrease in nasal resistance and improved sleep.

Of the pharmacological agents, most work has been carried out on intranasal steroids such as budesonide, flunisolide and fluticasone ${ }^{(22,23,28)}$. The pooled data (Table 1) of these drugs have demonstrated significantly improved nasal symptoms and sleep quality resulting in less daytime somnolence. Only one study ${ }^{(28)}$ however, has shown a slight lowering of the apnoeahypopnoea index (AHI) with fluticasone when compared with placebo but no difference in the sleep architecture was noted. Studies on decongestant such as oxymetazoline ${ }^{(29,30)}$ are limited and rather inconclusive; as data on snoring was not available but nasal resistance had improved in both studies as had the sleep architecture and the arousal index. However, it must be emphasised that such decongestants are only recommended for short-term use as prolonged usage will cause rhinitis medicamentosa.

\section{Nasal dilators}

These devices increase the ability to breathe through the nose by dilating the narrow nasal valve area by reducing the nasal resistance and thus theoretically improve snoring. There are two nasal dilators available: an externally applied Breathe Right $^{\circledR}$ and an internal device Nozovent ${ }^{\circledR}$. A handful of studies have been conducted with both devices and an improvement in snoring has been noted in a few ${ }^{(31-34)}$, but improvement in objective sleep parameters in only one study ${ }^{(31)}$. Nasal dilators are generally not recommended in patients with OSA but may be beneficial in a simple snorer with rhinitis and/or nasal valve collapse. In any case, they have no side effects and are not too expensive so would be worthy of trial in selected patients. If they help in improving symptoms then it may be worthwhile for the patient to be considered for definitive nasal valve surgery.

\section{Surgical treatment}

Nasal surgery is usually conducted to alter structural abnormalities present in primary snorer complaining of nasal obstruction and/or snoring. In addition to this group of patients there is a smaller group of patients that may present to the rhinologist for surgical intervention not for curative purposes but for adjunctive treatment to improve efficacy of their main treatment option of nasal continuous positive airway pressure (CPAP). Surgical procedures performed for SRBD includes septoplasty, septorhinoplasty, functional endoscopic sinus surgery, turbinate reduction and nasal valve surgery.

Studies published in the 80's and 90's on effects of septoplasty on snoring demonstrated reduction in snoring by $50-75 \%{ }^{(35-}$ 37). In these studies the surgical outcomes were purely measured subjectively using questionnaires or visual analogue scale. A

Table 1. Randomised Controlled Studies assessing nasal pharmacological interventions for sleep disturbance.

\begin{tabular}{|c|c|c|c|c|c|c|}
\hline Study & Study design & Patients & Nasal pathology & Intervention & Objective outcomes & Subjective outcome \\
\hline Kiely $2004^{(28)}$ & $\begin{array}{l}\text { Double blind } \\
\text { crossover RCT }\end{array}$ & $\begin{array}{l}10 \text { simple snorers } \\
\text { (mean AHI:3), } \\
13 \text { OSA patients } \\
\text { (mean AHI: } 26.5 \text { ) }\end{array}$ & $\begin{array}{l}\text { Allergic rhinitis, } \\
\text { no septal devia- } \\
\text { tion }\end{array}$ & $\begin{array}{l}\text { Fluticasone } 100 \mathrm{mcg} \\
\text { bd for } 4 \text { weeks }\end{array}$ & $\begin{array}{l}\text { Median AHI reduced } \\
\text { in OSA patients taking } \\
\text { fluticasone from } 30.3 \text { to } \\
23.0(\mathrm{p}<0.001)\end{array}$ & $\begin{array}{l}\text { Improvement } \\
\text { daytime alertness } \\
\text { for non apnoeic pa- } \\
\text { tients, not for OSA } \\
\text { patients }\end{array}$ \\
\hline Craig $2005^{(22)}$ & $\begin{array}{l}\text { Pooled results } \\
\text { from } 3 \text { double } \\
\text { blind ran- } \\
\text { domised crosso- } \\
\text { ver trials }\end{array}$ & $\begin{array}{l}42 \text { patients with } \\
\text { self reported day- } \\
\text { time somnolence } \\
\text { and impaired } \\
\text { sleep SA patients } \\
\text { excluded }\end{array}$ & $\begin{array}{l}\text { Subjective nasal } \\
\text { obstruction }\end{array}$ & $\begin{array}{l}\text { Nasal steroids od } \\
\text { (fluticasone } 200 \mathrm{mcg} \text {, } \\
\text { budesonide } 128 \mathrm{mcg} \text {, } \\
\text { flunisolide } 200 \mathrm{mcg} \text { ) } \\
\text { for } 3 \text { weeks }\end{array}$ & $\begin{array}{l}\text { Measured only in flutica- } \\
\text { sone group: No polysom- } \\
\text { nographic changes in AHI } \\
\text { or other sleep parameters }\end{array}$ & $\begin{array}{l}\text { Decreased sleep } \\
\text { problems and sleepi- } \\
\text { ness }\end{array}$ \\
\hline McLean $2005^{(30)}$ & $\begin{array}{l}\text { Double blind } \\
\text { crossover study }\end{array}$ & 10 OSA patients & $\begin{array}{l}\text { Clinician as- } \\
\text { sessed nasal } \\
\text { obstruction }\end{array}$ & $\begin{array}{l}\text { Topical xylometazo- } \\
\text { line }(0.2 \mathrm{mg} \text { twice }) \text { and } \\
\text { external dilator strip } \\
\text { for one night }\end{array}$ & $\begin{array}{l}\text { AHI reduced by } 12, \text { im- } \\
\text { proved sleep architecture }\end{array}$ & $\begin{array}{l}\text { No improvement in } \\
\text { daytime sleepiness }\end{array}$ \\
\hline Kerr $1992^{(29)}$ & $\begin{array}{l}\text { Double blind } \\
\text { crossover study }\end{array}$ & 10 OSA patients & $\begin{array}{l}6 \text { had clinician } \\
\text { and patient } \\
\text { assessed nasal } \\
\text { obstruction }\end{array}$ & $\begin{array}{l}\text { Topical xylometazo- } \\
\text { line before sleep and } \\
\text { internal nasal dilator } \\
\text { for one night }\end{array}$ & $\begin{array}{l}\text { No change in AHI, } \\
\text { slightly reduced arousal } \\
\text { episodes }\end{array}$ & $\begin{array}{l}\text { Subjective improve- } \\
\text { ment in sleep quality }\end{array}$ \\
\hline
\end{tabular}


more recent study by Virkkula et al. ${ }^{(38)}$ claimed that snoring is not relieved by nasal surgery despite improvement in nasal resistance. This study conducted on 40 Finnish patients presenting with snoring looked at the outcomes objectively using rhinomanometry, polysomnography and snoring intensity index. They concluded that the snoring time and intensity did not improve significantly in their patients. In contrast to this Finnish study, studies from Korea ${ }^{(39)}$ and Japan ${ }^{(40)}$, which looked at a different ethnic group claimed to have significant improvement in sleep parameters. This may appear to be the case if $p$ values are looked at e.g. reduction of the respiratory disturbance index (RDI) dropping from 39 preoperatively to 29.4 postoperatively giving a $p$ value of 0.0001 as reported by Kim et al. ${ }^{(39)}$, but closer analysis of the study reveals this not to be entirely true, particularly if Sher's criteria of reduction of more than $50 \%$ in RDI or AHI or the actual value to be less than 20 is applied ${ }^{(41)}$.

Li et al. ${ }^{(42,43)}$ have recently addressed the role of nasal surgery in patients with snoring and OSA from two different perspectives. Firstly, they looked at efficacy of nasal surgery to relieve snoring ${ }^{(42)}$, and tried to identify predictive factors concluding that the tonsil size affected the outcome of nasal surgery for snoring. Secondly, they looked at the important issue of improvement in QoL after nasal surgery alone for patients with OSA and nasal obstruction ${ }^{(43)}$. In this study, they evaluated QoL by using generic and disease specific questionnaires. They utilised the short-form health survey (SF 36), snore outcome survey and a separate spouse/bed partner survey. They concluded that by correcting an obstructed nasal airway, they were able to significantly improve disease specific and generic QoL thus substantiating the role of nasal surgery in treating these patients. However, in spite of the significant improvement noted in QoL parameters, disappointingly, there was no statistically significant improvement in the objective polysomnographic data. The disappointment in the lack of improvement documented objectively is shared by numerous other similar studies following nasal surgery alone for SRBD. Verse et al. ${ }^{(44)}$ studied a cohort of 26 patients of whom 19 had OSA and the remainder were simple snorers. A variety of nasal surgical procedures including septorhinoplasty, septoplasty, sinus surgery and nasal valve surgery were carried out. They concluded that although nasal surgery significantly improved sleep quality and daytime somnolence, the surgical response rate in the apnoeic group was in the region of $15 \%$ when looking at objective parameters of AHI. Four of their patients had worsening of OSA in spite of improving arousal index. This paradoxical effect can be explained by the so called 'first night effect' which implies that when the patient has the preoperative sleep study for the first time, they do not sleep well and as a result it may not truly reflect the severity of the SRBD; but with the subsequent postoperative sleep study they are already accustomed to the attachment of various leads and hence the recording on this occasion reflects more accurately the severity of the problem.
Morinaga et al. ${ }^{(45)}$ have looked at the way in which pharyngeal morphology could have an impact on the outcome of nasal surgery in patients with obstructive sleep apnoea and nasal obstruction. The pharyngeal morphological features they looked at included tonsil size, Mallampati score, narrowness of fauces and the retroglossal dimension. They concluded that a favourable nasal surgical outcome in this group of patients was seen in individuals who had a high positioned soft palate and/or in those with a wide retroglossal space. Unlike Li et al. ${ }^{(42)}$, they did not feel that the tonsil size affected the outcome of nasal surgery. The only randomised controlled study to date has been reported by Koutsourelakis et al. ${ }^{(46)}$ in which they assigned 49 patients with OSA and deviated nasal septum to either septoplasty or sham surgery and found that despite improvement in nasal patency as measured subjectively and objectively, there was no change in AHI or daytime sleepiness as measured by Epworth Sleepiness Scale.

The second group of patients that may be considered for nasal surgery are those who have failed CPAP therapy. The treatment of choice for moderate or severe OSA is CPAP but unfortunately many patients find this form of therapy cumbersome and is poorly tolerated with a compliance rate of less than $70 \%{ }^{(47)}$. CPAP therapy itself may cause rhinitis and may be poorly tolerated in the first place if the patient has any additional structural abnormality of the nose. More than $50 \%$ of CPAP users complain of significant nasal symptoms, including nasal congestion, rhinorrhoea, dryness and sneezing (48). Thus it is vital that patients who do not comply with or adhere poorly to CPAP therapy should undergo detailed evaluation of their upper airway to identify obstructive pathology that may be surgically correctable. This may lead to a reduction in the CPAP pressure and therefore improve the compliance of this form of therapy. Powell ${ }^{(49)}$ demonstrated this in a group of CPAP patients undergoing radiofrequency turbinate reduction. Patients in this study reported a subjective improvement in nasal obstruction, which in turn was linked to improved CPAP use. Similarly, Friedman et al. ${ }^{(50)}$ showed a significant decrease in CPAP titration levels following nasal surgery alone. In this study, reduction of pressure requirement for CPAP therapy was noted in patients with mild, moderate and severe OSA. The mean reduction of CPAP titration level was from $9.3 \mathrm{~cm} \mathrm{H} \mathrm{H}_{2} \mathrm{O}$ preoperatively to $6.7 \mathrm{~cm} \mathrm{H}_{2} 0$ postoperatively. This reduction in pressure would certainly help in improving the CPAP compliance.

\section{CONCLUSION}

It is now well recognised that reducing nasal resistance medically, surgically or with the use of dilators can improve sleep quality; however significant improvement in objective sleep parameters remain to be proven. In cases of severe nasal obstruction, as a compensatory response, patient starts mouth breathing, which can exacerbate the symptoms of SRBD. Although there is no role for nasal surgery alone in treating OSA, it is quite useful in improving symptoms 
in simple snorers and useful as part of multilevel surgery in many patients with SRBD. In CPAP failures if upper airway evaluation demonstrates an obstructive nasal passage then treating this certainly improves CPAP compliance and adherence. In general, if there is a positive response to medical treatment or with using nasal dilators then these patients may benefit from nasal surgical intervention.

\section{REFERENCES}

1. Rombaux Ph, Liistro G, Hamoir M, et al. Nasal obstruction and its impact on sleep-related breathing disorders. Rhinology. 2005; 43: 242-250.

2. American Sleep Disorders Association: International classification of Sleep Disorders (ICSD): Diagnostic and Coding Manual. American Sleep Disorders Association, Rochester, Minnesota, 1997, 21-24.

3. Stradling JR, Crosby JH. Predictors and prevalence of obstructive sleep apnoea and snoring in 1001 middle-aged men. Thorax. 1991; 46: 85-90.

4. Lugaresi E, Cirignotta F, Coccagna G, Piana C. Some epidemiological data on snoring and cardiocirculatory disturbances. Sleep. 1980; 3: 221-224.

5. Young T, Palta M, Dempsey J, Skatrad J, Weber S, Badr S. The occurrence of sleep-disordered breathing among middle-aged adults. N.Engl J Med. 1993; 328: 1230-1235.

6. Schwab RJ, Gefter WB, Hoffmann EA, Gupta KB, Pack AI. Dynamic upper airway imaging during awake respiration in normal subjects and patients with sleep disordered breathing. Am Rev Respir Dis. 1993; 148: 1385-1400.

7. Osbourne JE, Osman EZ, Hill PD, Lee BV, Sparkes C. A new acoustic method of differentiating palatal from non-palatal snoring. Clin Otolaryngol. 1999; 24: 130-133.

8. Kotecha BT, Hannan SA, Khalil HMB, Georgalas C, Bailey P. Sleep nasendoscopy: A 10-year retrospective audit study. Eur Arch Otorhinolaryngol. 2007; 264: 1361-1367.

9. Skatvedt O. Continuous pressure measurements during sleep to localise obstruction in heavy snorers and patients with obstructive sleep apnoea syndrome. Eur Arch Otorhinolaryngol. 1995; 252: 11-14.

10. Olsen KD, Kern EB, Westbrook PR. Sleep and breathing disturbance secondary to nasal obstruction. Otolaryngol Head Neck Surg. 1981; 89: 804-810.

11. Cole P, Haight JS. Mechanisms of nasal obstruction in sleep. Laryngoscope. 1984: 1557-1559.

12. Iber C, Berssengrugge A, Skatrud JB, Dempsey JA. Ventilatory adaptations to resistive loading during wakefulness and non-REM sleep. J Appl Physiol 1982; 52: 607-614.

13. Henke KG, Sullivan CE. Effects of high frequency pressure waves applied to upper airway on respiration in central sleep apnoea. J Appl Physiol. 1992; 73: 1141-1145.

14. Maurice JC, Mone I, Carrier G, Series F. Effects of mouth opening on upper airway collapsibility in normal sleeping subjects. Am J Respir Crit Care Med. 1996; 153: 255-259.

15. McNicholas WT, Coffey M, Boyle T. Effects of nasal airflow on breathing during sleep in normal humans. Am Rev Respir Dis. 1993; 147: 620-623.

16. White D, Cadieux R, Lombard RM, Bixler EO, Zwillich CW. The effects of nasal anaesthesia on breathing during sleep. Am Rev Respir Dis. 1985; 132: 972-975.

17. Kuna ST, Remmer JE. Neural and anatomic factors related to upper airway occlusion during sleep. Med Clin North Am. 1985; 69: 12211242.

18. Haight JS, Djupesland PG. Nitric oxide and obstructive sleep apnoea. Sleep Breath. 2003; 7: 53-62.

19. Wetmore SJ, Scrima L, Hiller FC. Sleep apnoea in epistaxis patients treated with nasal packs. Otolaryngol Head Neck Surg. 1988; 98: 596599.

20. Young T, Finn L, Palta M. Chronic nasal congestion at night is a risk factor for snoring in a population-based cohort study. Arch Inter Med. 2001; 161: 1514-1519.
21. Virkkula P, Bachour A, Hytönen M, Malamberg H, Salmi T, Maasilta P. Patient and bed partner reported symptom, smoking and nasal resistance in sleep-disordered breathing. Chest. 2005; 128: 21762182.

22. Craig TJ, Hanks CD, Fisher LH. How do topical nasal corticosteroids improve sleep and daytime somnolence in allergic rhinitis? J Allergy Clin Immunol. 2005; 116: 1264-1266.

23. Hughes K, Glass C, Ripchinski M, et al. Efficacy of the topical nasal steroid budesonide on improving sleep and daytime somnolence in patients with perennial allergic rhinitis. Allergy. 2003; 58: 380-385.

24. Settipane RA, Charnock DR. Epidemiology of rhinitis: allergic and nonallergic. Clin Allergy Immunol. 2007; 19: 23-34.

25. Fergusson BJ. Influence of allergic rhinitis on sleep. Otolaryngol Head Neck Surg. 2004; 130: 617-629.

26. Krouce HJ, Davis JE, Krouse JH. Immune mediators in allergic rhinitis and sleep. Otolaryngol Head Neck Surg. 2002; 126: 607-613.

27. Kohler M, Clarenbach CF, Thurnheer R, Bloch KE. Perception of nocturnal nasal obstruction in chronic rhinitis. Eur Respir J. 2005; 26: Suppl 49, 565.

28. Kiely JL, Nolan P, McNicholas WT. Intranasal corticosteroid therapy for obstructive sleep apnoea in patients with co-existing rhinitis. Thorax. 2004; 59: 50-55.

29. Kerr P, Millar T, Buckle P, Kryger M. The importance of nasal resistance in obstructive sleep apnoea syndrome. J Otolaryngol. 1992; 21: 189-195.

30. McLean HA, Upton AM, Driver HS. Effect of treating nasal obstruction on the severity of obstructive sleep apnoea. Eur Respir J. 2005; 25: 521-527.

31. Höijer U, Einell H, Hedner J, Petrusson B. The effect of nasal dilatation on snoring and obstructive sleep apnoea. Arch Otolaryngol Head Neck Surg. 1992; 18: 281-284.

32. Pevernagie D, Hamans E, Van Cauwenberge P, Pauwels R. External nasal dilators reduces snoring in chronic rhinitis patients: a randomised controlled trial. Eur Respir J. 2000; 15: 996-1000.

33. Djupesland PG, Stakvedt O, Borgersen A. Dichotomous physiological effects of nocturnal external dilatation in heavy snorers: the answers to a rhinologic controversy. Am J Rhinology. 2001; 15: 95-103.

34. Gosepath J, Amedee R, Romanstschuk S, Mann W. Breathe Right nasal strips and respiratory disturbance index in sleep related breathing disorders. Am J Rhinology. 1999; 13: 385-389.

35. Low WK. Can snoring relief after nasal septal surgery be predicted? Clin Otolaryngol. 1994; 19: 142-144.

36. Ellis PDM Harries MLL, Williams JE, Shneerson JM. The relief of snoring by nasal surgery. Clin Otolaryngol. 1992; 17: 525-527.

37. Fairbanks DNF. Effect of nasal surgery on snoring. South Med J. 1985; 78: 268-270.

38. Virkkula P, Bachour A, Hytönen M, et al. Snoring is not relieved by nasal surgery despite improvement in nasal resistance. Chest. 2006; 129: 81-87.

39. Kim ST, Choi JH, Jeen HG, Cha HE, Kim DY, Ching YS. Polysomnographic effects of nasal surgery for snoring and obstructive sleep apnoea. Acta Otolaryngol. 2004; 124: 297-300.

40. Nakata S, Noda A, Yasuma F. Effects of nasal surgery on sleep quality in obstructive sleep apnoea syndrome with nasal obstruction. Am J Rhinol. 2008; 22: 59-63.

41. Sher A, Schechtman KB, Piccirillo JF. The efficacy of surgical modification of the upper airway in adults with obstructive sleep apnoea syndrome. Sleep. 1996; 19: 156-177.

42. Li HY, Lee LA, Wang PC, Chen NH, Lin Y, Fang TJ. Nasal surgery for snoring in patients with obstructive sleep apnoea. Laryngoscope. 2008; 118: 354-359.

43. Li HY, Lin Y, Chen NH, Lee LA, Fang TJ, Wang PC. Improvement in quality of life after nasal surgery alone for patients with obstructive sleep apnoea and nasal obstruction. Arch Otolaryngol Head Neck Surg. 2008; 134: 429-433.

44. Verse T, Maurer JT, Pirsig W. Effect of nasal surgery on sleep-related breathing disorders. Laryngoscope. 2002; 112: 64-68.

45. Morinaga M, Nakata S, Yasuma F, Noda A, Yagi H, Tagaya M, Teranishi M. Pharyngeal morphology: A determinant of successful nasal surgery for sleep apnoea. Laryngoscope. 2009; 119: 1011-1016. 
46. Koutsourelakis I, Georgoulopoulos G, Perraki E, Vagiakis E, Roussos C, Zakynthinos SG. Randomised trial of nasal surgery for fixed nasal obstruction in obstructive sleep apnoea. Eur Respir. J. 2008; 31: 110-117.

47. McArdle N, Dervereux G, Heidarnejad H, Engleman HM, Mackay TW, Douglas NJ. Long-term use of CPAP therapy for sleep apnea/ hypopnea syndrome. Am J Respir Crit Care Med. 1999; 159: 11081114.

48. Hoffstein V, Viner S, Mateika S, Conway J. Treatment of obstructive sleep apnea with nasal continuous positive airway pressure. Am Rev Respir Dis. 1992; 145: 841-845.

49. Powell N. Radiofrequency treatment of turbinate hypertrophy in subjects using CPAP: a randomized double-blind, placebo-controlled trial. Laryngoscope. 2001; 111: 1783-1790.

50. Friedman M, Tanyeri H, Lim JW, Landsberg R, Vaidyanathan K, Caldarelli D. Effect of improved nasal breathing on obstructive sleep apnea. Otolaryngol Head Neck Surg. 2000; 122: 71-74.
Bhik Kotecha, M.Phil., FRCS, DLO

Consultant Otolaryngologist

Royal National Throat, Nose \& Ear Hospital

330 Grays Inn Road

London WC1X 8DA

United Kingdom

E-mail: bhikkot@aol.com 